\title{
Effect of extraction method on Mycochemicals and Proximate composition of Pyrrhoderma noxium (Corner) L.W. Zhou \& Y.C. Dai, (Hymenochaetales, Basidiomycota)
}

\author{
Nagadesi PK ${ }^{1 *}$, Naveen Babu $\mathrm{D}^{2}$, Suneetha $\mathrm{NN}^{2}$, Prasad $\mathrm{KSM}^{2}$ and Devi PP${ }^{2}$ \\ ${ }^{1}$ Department of Botany, P.G. Block, Andhra Loyola College, Near Gunadala, Vijayawada-8, Andhra Pradesh, India. \\ ${ }^{2}$ Department of Biochemistry, $R \&$ D Wing, St. Joseph Dental College, Duggirala, Eluru, Andhra Pradesh, India
}

Nagadesi PK, Babu ND, Suneetha NN, Prasad KSM, Devi PP 2019 - Effect of extraction method on Mycochemicals and Proximate composition of Pyrrhoderma noxium (Corner) L.W. Zhou \& Y.C. Dai, (Hymenochaetales, Basidiomycota). Studies in Fungi 4(1), 223-229, Doi 10.5943/sif/4/1/24

\begin{abstract}
Several medicines obtained from Pyrrhoderma mushrooms are widely used against several diseases throughout the world. So, in preparation of crude drugs/ folk medicines of mushroom i.e. Pyrrhoderma noxium collected from Krishna district, Andhra Pradesh, India was studied and identified phenotypically. The present work aims to test the presence of Mycochemicals and proximate composition for standardization of powder of $P$. noxium. The solvents used for extraction and method of extraction played a vital role on mycochemical and proximate composition of $P$. noxium sporophore. The maceration water bath assisted extraction method is the best extraction method compared to maceration and Reflux extraction methods for all parameters studied in this work. The present study shows the extraction method and type of solvent influencing the presence of mycochemical composition like alkaloids, carbohydrates, phenols, flavonoids, tannins, terpenoids, diterpenoids, and anthocyanin in hymenochaetales fungi. The proximate composition evaluation is very much useful for standardisation of $P$. noxium in powder form. That will help to identify the genuine species and check for adulteration of powder available commercially.
\end{abstract}

Key words - Extraction type - Hymenophore - Phytochemicals - Phenotypical - Phellinus noxius

\section{Introduction}

Allopathic medicines prepared from pharmaceutical industry are costly, have various side effects, and are not safe for use. So alternative to synthetic drugs, medicines prepared from natural herbal sources are in great demand in these days. Medicines prepared from mushrooms are widely used against several diseases throughout the world (Chenghom et al. 2010). hymenophores of Pyrrhoderma is used as folk medicine for curing different diseases since ancient times(Chenghom et al. 2010). Pyrrhoderma is reported to contain different bioactive compounds, such as carbohydrates, proteins, phenols, alkaloids, terpenoids, polysaccharides, steroids and fatty acids (Lahiri et al. 2010, Nagadesi et al. 2016). The phytochemicals, physicochemical and mycochemical aspects have not been studied for every Pyrrhoderma species. In this study phenotypical, mycochemical, proximate composition of $P$. noxium is carried out for the specimens collected from Krishna district, Andhra Pradesh, India. This research also helps to establish the standards for identity, quality, purity and mycochemical composition of $P$. noxium. 


\section{Materials \& Methods}

\section{Collection of Hymenochaetales fungi}

The sporophores of Pyrrhoderma noxium was collected from Andhra Pradesh, India, during the rainy season (July-September) of the years 2014 to 2017. Field characters like habit, host, name of locality, and other macro-morphological characteristics were recorded for sample specimens. Voucher specimen of P. noxium (ALC 25) has been deposited at the herbarium of the Museum of Botany Department, Andhra Loyola College, Vijayawada, Andhra Pradesh, India (ALC).

\section{Phenotypical identification}

For identification of hymenophore different Macroscopic features like abhymenial, hymenial surfaces, context, and pore tubes of species were examined. Microscopic features like hyphae, basidiospores and pilear crust were observed by preparing crush mounts and free-hand sections in water, $5 \% \mathrm{KOH}$ solution, and staining was done with cotton blue (1\%, in lactophenol), Congo red ( $1 \%$, in distilled water), phloxine (1\%, in distilled water), and Melzer's reagent (Nagadesi et al. 2016).

\section{Preparation of Extraction}

The fruiting bodies of $P$. noxium were initially rinsed thrice in distilled water and dried on paper towels and samples was cut into fine pieces and powdered. For preparing the extracts water, methanol, and ethanol were used as solvents.

\section{Maceration}

5 grams of sporophore powder were soaked in $100 \mathrm{ml}$ of water, methanol and ethanol, separately. All the samples were left at room temperature for $24 \mathrm{hr}$. Then the samples were filtered through whatman filter paper No.1 pore size and further used for mycochemical qualitative and quantitative tests.

\section{Maceration Water Bath}

$5 \mathrm{~g}$ of sporophore powder were soaked in $100 \mathrm{ml}$ of water, methanol and ethanol, separately. All the samples were heated in Maceration Water Bath at $600^{\circ} \mathrm{C}$ for 1 hour. Then the samples were filtered through whatman filter paper No.1 pore size and further used for mycochemical qualitative and quantitative tests.

\section{Reflux apparatus}

For every 5 gram of powder, $100 \mathrm{ml}$ of solvent was used and was subjected to extraction using a reflux apparatus. After the completion of extraction, the supernatant was filtered through Whatman No. 1 filter paper. The filtrates were stored at $4{ }^{\circ} \mathrm{C}$ to perform various assays for determination of bioactivity mycochemicals.

\section{Screening of Bioactive Mycochemical}

The screening of bioactive mycochemicals in fresh sporophores of $P$. noxium were tested by using standard methods followed by Evans \& Trease 1989, Gokhale 1993, Trease \& Evans 1996, Harborne 1973).

\section{Proximate composition}

To establish standards for their identity, quality, purity of hymenophore powder the proximate composition was carried out for P. noxiun collected from Krishna district, Andhra pradesh, India. The pulverized sporophore of $P$. noxium was used for the standardization of physicochemical parameters in triplicate. Foreign matter, moisture content, extractive values, ash values (Gaithersburg 2000, Indian Pharmacopoeia Commission 2007) dry matter (Kornerup \& Waanscher 1978), absorption properties, foaming properties (Aremu et al. 2007), emulsion values 
(Yatsumatsu et al. 1972), dispersibility (Kulkarni \& Ingle 1991), flow characteristics, swelling index (Prodhan et al. 2015) were determined.

\section{Results}

\section{Phenotypical identification}

\section{Pyrrhoderma noxium (Corner) L.W. Zhou \& Y.C. Dai, Mycologia 110 (5): 882 (2018)}

Basidiocarps perennial, imbricate, effused-reflexed, woody hard, light in weight when dry, $18 \mathrm{~cm}$ wide $10 \mathrm{~cm}$ broad, $6 \mathrm{~cm}$ thick near the base, upper surface black, glabrous, with a hard crust, azonate, frequently nodulose at the center, margin, obtuse, entire, yellowish brown; pore surface reddish brown, tubes distinctly layered, $2 \mathrm{~mm}$ deep in each layer, pores small 6-8 per mm, angular, moderately thick-walled entire, darker than the context. Context: $2 \mathrm{~cm}$ thick at base, zoned, pale brown, radially fibrous; hyphal system dimitic, setal hyphae present, $6.2-15.6 \mu \mathrm{m}$ wide, up to 4.2 $\mu \mathrm{m}$ long, rare and narrow in context, frequently projecting into the lumen of tubes, dark reddish brown, tips obtuse; hymenial setae absent, Basidia hyaline, 5.2 - $8.3 \times 3.1-5.2 \mu \mathrm{m}$, Basidiospores hyaline, subglobose, smooth, thin-walled, $2.1-3.8 \times 2.1 \mu \mathrm{m}$.

\section{Preparation of Extraction}

Three extraction methods were employed in order to obtain the biologically active mycochemical components in water, methanol, ethanol and 50\% hydro-methanol as solvents. The Maceration Water bath extraction shown better mycochemical and proximate composition when compared to Maceration and Reflux apparatus extraction methods.

\section{Effects of extraction method on Mycochemical composition in $P$. noxium}

Mycochemical compounds screening of water, methanol, ethanol and 50\% Hydro-methanol extracts of $P$. noxium were prepared by using Maceration, Maceration Water bath, Reflux apparatus methods and the results of the effect of extraction methods and solvent on mycochemical compounds are presented in Tables 1 . The best extraction method for $P$. noxium is maceration water bath extraction because almost all mycochemicals are extracted. The best solvent for preparation of $P$. noxium extraction in all three methods is methanol because all tests for mycochemical composition shown positive. The methanol extract of $P$. noxium prepared by maceration water bath showed excellent concentration of alkaloids, carbohydrates, phenols, flavonoids, tannins, terpenoids, diterpenoids, and Anthocyanin; the ethanol extract showed excellent concentration of alkaloids, phenols, flavonoids, tannins, terpenoids, diterpenoids, and Anthocyanin; 50\% hydromethanol showed phenols, flavonoids, tannins, terpenoids.

\section{Proximate composition}

The hymenophore powder of $P$. noxium shows the proximate composition in Table 2 . Foreign matter present in sporophore powder of $P$. noxium is $0.03 \%$ whereas moisture content in sporophore powder of $P$. noxium is $7.4 \%$. The higher the dry matter in sporophore of $P$. noxium indicate presence of less moisture. The extractive value of powder of $P$. noxium shows higher ethanol soluble value when compared to water soluble content. The ash content of sporophore powder of $P$. noxium shown higher water soluble ash when compared to acid insoluble ash. The absorption of sporophore powder of $P$. noxium shown higher water absorption when compared to oil absorption. The emulsion formation capacity of sporophore of $P$. noxium shown higher dispersibility when compared to emulsion stability. The flowing properties of sporophore powder of $P$. noxium shown tapped density is more when compared to bulks density. The sporophore powder of $P$. noxium shown higher foaming capacity. 
Table 1 Mycochemicals screening of different extracts of $P$. noxium

\begin{tabular}{|c|c|c|c|c|c|c|c|c|c|c|}
\hline $\begin{array}{l}\text { Extraction by } \\
\text { maceration }\end{array}$ & Alkaloid & $\begin{array}{l}\text { Carbohydrate } \\
\text { s }\end{array}$ & Proteins & $\begin{array}{l}\text { Amino } \\
\text { Acids } \\
\end{array}$ & Tannins & Flavonoids & Phenols & Terpenoids & Di Terpenoids & Anthocyanins \\
\hline Water & ++ & +++ & ++ & - & ++ & + & ++ & + & + & + \\
\hline Methanol & +++ & +++ & + & + & +++++ & +++++ & +++ & +++++ & ++++ & +++ \\
\hline Ethanol & +++ & ++ & ++ & + & +++++ & +++++ & +++ & +++++ & +++ & +++ \\
\hline $50 \%$ methanol & +++ & +++ & ++ & - & +++ & +++ & +++ & +++ & ++ & ++ \\
\hline $\begin{array}{l}\text { Extraction by } \\
\text { Water Bath } \\
\end{array}$ & Alkaloid & $\begin{array}{l}\text { Carbohydrate } \\
\text { s }\end{array}$ & Proteins & $\begin{array}{l}\text { Amino } \\
\text { Acids }\end{array}$ & Tannins & Flavonoids & Phenols & Terpenoids & Di Terpenoids & Anthocyanins \\
\hline Water & +++ & ++++ & +++ & + & +++ & ++ & +++ & ++ & ++ & ++ \\
\hline Methanol & ++++ & ++++ & ++ & ++ & ++++++ & +++++ & ++++ & ++++++ & +++++ & ++++ \\
\hline Ethanol & ++++ & +++ & +++ & ++ & ++++++ & ++++++ & ++++ & ++++++ & ++++ & ++++ \\
\hline $50 \%$ methanol & +++ & ++ & +++ & + & ++++ & ++++ & ++++ & ++++ & +++ & +++ \\
\hline $\begin{array}{l}\text { Extraction by } \\
\text { reflux } \\
\text { apparatus }\end{array}$ & Alkaloid & $\begin{array}{l}\text { Carbohydrate } \\
\text { s }\end{array}$ & Proteins & $\begin{array}{l}\text { Amino } \\
\text { Acids }\end{array}$ & Tannins & Flavonoids & Phenols & Terpenoids & Di Terpenoids & Anthocyanins \\
\hline Water & ++ & ++ & + & - & ++ & ++ & ++ & ++ & ++ & ++ \\
\hline Methanol & ++ & ++ & + & - & ++++ & ++++ & +++ & ++++ & +++ & +++ \\
\hline Ethanol & ++ & + & + & - & ++++ & ++++ & +++ & ++++ & +++ & ++ \\
\hline $50 \%$ methanol & +++ & +++ & + & - & +++ & ++ & ++ & ++ & ++ & ++ \\
\hline
\end{tabular}

$+=$ present, ++ (or) $+++=$ moderately present, ++++ (or) $+++++=$ Excellent

\section{Discussion}

\section{Mycochemical compounds}

P. noxium showed positive reactions to bioactive compounds like Alkaloid, Tannins, Flavonoids, Phenols, Terpenoids, Diterpinoids, and Anthocyanins in both Methanol and Ethanol extracts (Nagadesi et al. 2016). In the present study, the mycochemical composition of water methanol ethanol and 50\% Hydromethanol is studied and the methanol is best solvent shown all the compounds tested. For the first time the carbohydrate, proteins, amino acids are shown positive results in all extraction methods and solvents of $P$. noxium.

\section{Proximate composition}

Foreign matter present in a sample or drug masks its quality and purity. Therefore it cannot be neglected. A very small amount of foreign matter was noticed i.e. $0.16 \%$ in $P$. gilvus and $0.02 \%$ in P. torulosus respectively (Azeem et al. 2018). In this study, very small amount of foreign matter is shown by $P$. noxium (0.03\%). The higher the moisture content, the greater is the degradation of the mushroom sample due to enhanced microbial 
growth and hydrolytic enzyme activity. The moisture content in the $P$. torulosus is $11 \%$ and $P$. gilvus is $21.33 \%$ (Azeem et al. 2018). In the present study, the moisture content of $P$. noxium is less (7.46\%) when compared to $P$. torulosus $P$. gilvus. Dry matter of sporophore powder of $P$. gilvus is 78.67 and $P$. torulosus is $89.1 \%$ (Azeem et al. 2018). In the present paper, the dry matter of $P$. noxium is $90 \%$. Extractive values indicate that each tested mushroom had greater alcohol soluble polar constituents i.e. $2.93 \%$ in $P$. gilvus and $2.33 \%$ in $P$. torulosus than water soluble constituents i.e. $1.73 \%$ in $P$. gilvus and $1.83 \%$ in P. torulosus (Azeem et al. 2018). In the present paper, the extractive values like alcohol soluble polar constituents and water soluble constituents of $P$. noxium is high when compared to $P$. gilvus $P$. torulosus Ash content provides an indication of earthy material or inorganic compounds in the drug. The ash content of mushrooms was found in the range 1.3-6.3\% estimated for Phellinus linteus (Gordon 1993). The ash content in sporophore powder of $P$. gilvus is $4.33 \%$ and $P$. torulosus is 3.83\% respectively (Azeem et al. 2018). In the present paper, the total ash content in sporophore powder of $P$. noxium is $5.25 \%$. Water soluble ash indicates the amount of inorganic constituents in herbal drugs. Acid insoluble ash gives an idea of silica present and contamination with earthy material. The values for acid insoluble ash for $P$. gilvus is $1.66 \%$ and $P$. torulosus is $1.5 \%$ and water soluble ash content in $P$. torulosus powder is $1.0 \%$ and $P$. gilvus powder is $1.5 \%$ (Azeem et al. 2018). In the present paper, the water soluble and acid soluble ash of $P$. noxium is high when compared to $P$. gilvus $P$. torulosus.

Table 2 Proximate composite evaluation in sporophore of $P$. noxium

\begin{tabular}{|l|l|l|}
\hline Parameters & & P. noxious \\
\hline & Foreign matter (\%) & 0.03 \\
\hline & Moisture content (\%) & 7.46 \\
\hline & Dry matter (\%) & 90 \\
\hline & Ethanol soluble extractives & 4.23 \\
\hline & Water soluble extractives & 3.4 \\
\hline Ash content (\%) & Total ash & 5.25 \\
\hline & Acid insoluble ash & 2.12 \\
\hline Absorption properties (ml/g) & Water soluble ash & 4.5 \\
\hline & Oil absorption capacity & 9.45 \\
\hline Emulsion properties (\%) & Water absorption capacity & 63.63 \\
\hline & Emulsifying capacity & 30.65 \\
\hline & Emulsion stability & 21.35 \\
\hline Flow properties & Dispersability (\%) & 50 \\
\hline & Bulk density (g/ml) & 1.3 \\
\hline Foaming properties (\%) & Tapped density (g/ml) & 1.8 \\
\hline & Foaming capacity & 48.80 \\
\hline & Foaming stability & 37.63 \\
\hline & Swelling Index (\%) & 40 \\
\hline
\end{tabular}

Imbibition of water is an important trait in food products such as sausages, custards and doughs. Water absorption depends on amount and type of hydrophilic constituents, $\mathrm{pH}$ and nature of the powder (Omimawo \& Akubor 2012). Oil absorption capacity indicates the rate at which proteins bind to fats in food and drug formulations (Khan et al. 2011). Phellinus torulosus had higher oil absorption capacity and water absorption capacity than P. gilvus (Azeem et al. 2018). In the present paper, the absorption of water and oil of $P$. noxium is high when compared to other phellinus samples. Emulsion capacity is the ability of powder to emulsify oil. Emulsions play a crucial role in pharmaceutical preparations like cosmetics, pastes etc. Emulsions have also been used for treating skin disorders, lacerations and for drug delivery etc. (Dickinson 1994). Certain biochemical constituents too help in stabilizing the emulsion (Narayana \& Rao 1982). Phellinus torulosus showed greater emulsion capacity and emulsion stability (Azeem et al. 2018). In the present paper, the emulsion capacity and emulsion stability is $30.65 \%$ and $21.35 \%$ respectively. 
Bulk density is a measure of heaviness of powder which provides the relative volume of the packaging material required. Dispersibility of powder in water gives an idea of its reconstitutability. Both the studied $P$. gilvus and $P$. torulosus showed good bulk density i.e. $0.14 \mathrm{~g} / \mathrm{ml}$ and $0.19 \mathrm{~g} / \mathrm{ml}$ respectively and dispersibility of $P$. gilvus is 83.67 and for $P$. torulosus is $84.33 \%$ (Azeem et al. 2018). In the present study, the bulk density and dispersibility of $P$. noxium is $50 \%$ and $1.3 \mathrm{~g} / \mathrm{ml}$ respectively. Flow properties indicate that powder may be utilized as a direct compression excipient. Hausner ratio provides inter particle friction and Carr's index is a measure of compressibility of powder. Hausner ratio and Carr's index of Phellinus torulosus was observed lower than 1.25 and $15 \%$ respectively indicating good flow properties (Azeem et al. 2018). In the present study, the flow properties like tap density of $P$. noxium is $1.8 \mathrm{~g} / \mathrm{ml}$. Foaming capacity is the ability of a powder to form foam. It is related to the amount of solubilised proteins (Nwokolo 1985) and polar and non-polar lipids in the sample (Akubor \& Eze 2012). Saponins also play a role in foam formation. Foams are used to improve texture, consistency and appearance of food and drug (Akata et al. 2012). There was no observed foam formation in any of the tested mushroom samples (Azeem et al. 2018). In this work the foam formation is shown by P. noxium. The powder of all tested Phellinus mushroom did not swell indicating lack of mucilage substances (Azeem et al. 2018). In the present study the sporophore powder of $P$. noxium showed presence of mucilage like substance. The sensory evaluation of powder of $P$. noxium provides useful information which may prove helpful in authentication and detection of adulteration for quality control.

\section{Acknowledgements}

The authors are thankful to the Principal, Vice principal (P.G), Andhra Loyola college, Vijayawada-8, for laboratory facilities in Botany Department. Prof. Arun arya, Head Environmental Science, Faculty of Science, The Maharaja Sayajirao University of Baroda, vadodara, for identification conformation of fungi.

\section{References}

Akata I, Ergönül B, Kelyoneu F. 2012 - Chemical compositions and antioxidant activities of 16 wild edible mushroom species grown in Anatolia. International Journal of Pharmacology, 8, 134-138.

Akubor PI, Eze JI. 2012 - Quality evaluation and cake making potential of sun and oven dried carrot fruit. International Journal of Biosciences, 2, 19-27.

Aremu MO, Olaofe O, Akintayo ET. 2007 - Functional properties of some Nigerian varieties of legume seed flour and flour concentration effect on foaming and gelation properties. Journal of Food Technology, 5, 109-115.

Azeem U, Dhingra GS, Shri R. 2018 - Evaluation of Taxonomy, Physicochemical Parameters, and Mycochemical Composition of Wood Decaying Indian Fungi Phellinus gilvus (Schwein.) Pat. and Phellinus torulosus (Pers.) Bourdot \& Galzin: A Comparative Study International Journal of Phytopharmacy Research 9(1),17-25.

Chenghom O, Suksringram J, Morakot N. 2010 - Mineral composition and Germanium contents in some Phellinus mushrooms in the Northeast of Thailand. Current Research in Chemistry. 2(2), 24-34.

Dickinson E. 1994 - Protein-stabilized emulsions. Journal of Food Engineering, 22, 59-74.

Evans WC, Trease GE. 1989 - Pharmacognosy 13th ed., Bailliere Tindall, London.

Gaithersburg MD. 2000 - AOAC. Official methods of analysis of the Association of Official Analysis Chemists (17th ed.), AOAC international.

Gokhale SB, Kokate CK, Purohit AP. 1993 - A text book of Pharmacognosy. Published by Nirali Prakshan, Pune, India, 1-50.

Gordon MS. 1993 - Simulation tools for the thermal processing of foods. Food Technology, Phytochemical Methods. Chapman and Hall, London. 
Harborne JB. 1973 - Phytochemical Methods: A Guide to Modern Techniques of plants Analysis, 3st Edn., Chapman and Hall, Madras, pp 302.

Indian Pharmacopoeia Commission. 2007 - Indian Pharmacopoeia. Vol.1. New Delhi: Government of India Press.

Khan BA, Akhtar N, Khan HMS. 2011 - Basics of pharmaceutical emulsions: a review. African Journal of Pharmacy and Pharmacology, 5, 2715-2725.

Kornerup A, Waanscher JH. 1978 - Metheun's handbook of colors. 3rd ed. Metheun and Co. Ltd. London, pp 252.

Kulkarni DN, Ingle UM. 1991 - Sorghum malt based weaning food formulations: preparation, functional properties, and nutritive value. Journal of Food and Nutrition, 13, 322-323.

Lahiri SK, Gokania RH, Shuklab MD, Modic HA et al. 2010 - Evaluation of Antioxidant Activity of Plant-parasitic Macrofungus: Phellinus durissimus (Lloyd) Roy. Eurasian Journal of Analytical Chemistry, 5(1), 32-45.

Nagadesi PK, Aravind G, Kannamba B. 2016 - Taxonomy and Bioactive chemicals from Ganoderma and Phellinus of India. Biological Forum An international Journal, 8(2), 240246.

Narayana K, Rao NMS. 1982 - Functional properties of raw and heat processed winged bean (Psophocarpus tetragonolobus) flour. Journal of Food Science, 47, 1534-1538

Nwokolo E. 1985 - Nutritional quality of the seeds of the African breadfruit (Treculia africana Decne). Tropical Science, 27, 39-47.

Omimawo IA, Akubor PI. 2012 - Food Chemistry (Integrated Approach with Biochemcial background). Agbowo, Ibadan, Nigeria

Prodhan UK, Linkon KMdMR, Al-Amin MdF, Alam MdJ. 2015 - Development and quality evaluation of mushroom (Pleurotus sajor-caju) enriched biscuits Emirates Journal of Food and Agriculture. 27(7), 542-547, doi: 10.9755/ejfa.2015.04.082

Trease GE, Evans WCA. 1996 - Textbook for pharmacognosy, 14th Eds. Saunders, W.B (Ed), London. pp 13-53.

Yatsumatsu K, Sawuda K, Moritaka S, Miscki M. 1972 - Whipping and emulsifying properties of soybean products. Journal of Agaricultural and Biological Chemistry, 36, 719-726. 